\title{
Lean Office - escritório enxuto: estudo da aplicabilidade do conceito em uma empresa de transportes
}

Clésia de Souza Evangelista

clesias@hotmail.com

Fernanda Machado Grossi

fegrossi@yahoo.com.br

Raoni Barros Bagno

rbbagno@gmail.com

\section{RESUMO}

Este estudo explorou a aplicabilidade dos conceitos relacionados ao Lean Manufacturing (produção enxuta) em áreas administrativas da produção, tomando-se a área de expedição de uma transportadora como caso de análise. Partindo de conceitos criados originalmente para ambientes de manufatura, o Lean Office (escritório enxuto) é a tradução dos princípios do Lean Manufacturing aos processos administrativos. Este artigo traz, inicialmente, uma revisão bibliográfica relacionada ao Lean Office, suas origens e métodos de implantação. Através de uma estratégia metodológica orientada para a intervenção direta no ambiente de estudo, foi possível analisar o mapa de fluxo de valor de um dos processos da empresa, identificar desperdícios e propor melhorias. Ao final, desenvolve-se uma disussão pautada nos resultados práticos e nas dificuldades encontradas na implantação dos novos conceitos, valorizando também a variável social do sistema produtivo em estudo. Por fim, conclui-se que os conceitos do Lean Office apresentaram-se como promissores no recorte de campo analisado e são potencialmente extensíveis a diferentes setores e empresas, tendo em conta as devidas adaptações contextuais relativas a cada organização.

Palavras-chave: Lean Office; Áreas administrativas; Desperdícios.

\section{Lean Office: a study of this concept's applicability to a transportation company}

\begin{abstract}
This study aims to explore the applicability of Lean Manufacturing concepts to administrative departments and takes a transportation company as a case study. Based on the concepts originally proposed for manufacturing environments, Lean Office proposes a translation of Lean Manufacturing principles to administrative processes. The article starts with a literature review about the main concepts of Lean Office, its origin and implementation method. The methodology makes use of direct involvement in the environment under study. Some of the activities performed were the Value Stream Mapping of the company's process selected; identification of wastes; and the proposition of improvements to be implemented. Finally, practical results motivate a discussion on the real potential of Lean Office principles and on the challenges related to its implementation, highlighting also the social perspective of the production environment. The main conclusion is that lean office is a promising management approach for the case studied and the findings also suggest that its principles are potentially generalizable to other departments or even to other companies, provided that the necessary contextualization demanded for each organizational environment is present.
\end{abstract}

Key words: Lean office; Administrative departments; Wastes. 


\section{Introdução}

Um dos objetivos centrais do Sistema Toyota de Produção (STP) sempre foi aumentar a eficiência da produção pela eliminação consistente e completa do desperdício. Segundo Womack e Jones (2004), Eiji Toyoda e Taiichi Ohno, após a Segunda Guerra Mundial foram os pioneiros no conceito de "produção enxuta". À medida que se percebeu a necessidade da reconstrução de seu parque industrial, outras companhias e indústrias japonesas se espelhariam paulatinamente nesse conceito. Para esses autores, o pensamento enxuto é uma forma de fazer cada vez mais com menos menos esforços, menos equipamentos, menos tempo e menos espaços - e, ao mesmo tempo, aproximar-se cada vez mais do ideal de se oferecer aos clientes exatamente o que eles desejam.

Eliminar desperdício e enxugar os processos das empresas é torná-la Lean. Enxugar processos implica esforço contínuo para alcançar o mínimo desperdício e o máximo fluxo produtivo. Isso requer mudança organizacional disparada por uma mudança de mentalidade, que nasce no nível estratégico de uma organização e deve ser desdobrada e assimilada até o nível operacional.

Com a disseminação desse conceito e a necessidade crescente das empresas em se tornarem cada vez mais enxutas, eliminando elementos que não agregam valor a seus processos, nasce o Lean Office (escritório enxuto), que se baseia, então, na aplicação de princípios e ferramentas oriundos do Lean Manufacturing às atividades administrativas das organizações. No contexto dos sistemas produtivos, o Lean Office vem aderir-se, especialmente, aos fluxos de informações que não acompanham os processos de material ou de fabricação. Intenta manter, contudo, objetivos ligados à redução de custos, eliminação de retrabalho, minimização de problemas de comunicação, redução e eliminação de atividades que não agregam valor aos processos, aumento de produtividade, eficiência das funções administrativas e melhor utilização da área de trabalho nos ambientes administrativos (TAPPING; SHUKER, 2010; TURATI, 2007; WOMACK; JONES, 2004; OHNO, 1997).

Este estudo busca levantar os principais pontos relacionados à aplicabilidade dos conceitos do Lean Office nas organizações e toma o caso da área de expedição de uma transportadora localizada no Estado de Minas Gerais como ambiente de experimentação e fonte de reflexão acerca dos passos de implantação do conceito.

O texto que se segue está organizado da seguinte forma: na seção 2 é realizado um levantamento bibliográfico contemplando aspectos conceituais e históricos da manufatura enxuta e seu desdobramento ao conceito de escritórios enxutos. $\mathrm{Na}$ seção 3 é apresentada a abordagem metodológica, que converge para o aspecto intervencionista do arcabouço da pesquisa-ação. A seção 4 apresenta a pesquisa de campo, cujas particularidades são discutidas na seção 5, à luz da bibliografia anteriormente levantada. Por fim, na seção 6 encontram-se as conclusões e perspectivas para novos estudos sobre o tema.

\section{Revisão bibliográfica}

\subsection{Produção enxuta}

A indústria automobilística configura-se como grande celeiro de métodos e técnicas aplicados à Engenharia de Produção, como exemplificado pela produção em massa de Henry Ford e a produção enxuta de Toyoda Sakichi e Taiichi Ohno. O Sistema Toyota de Produção (STP) vem nascer logo após a Segunda Guerra Mundial, atraindo a atenção de todo o mundo a partir da crise do petróleo, no outono de 1973 (OHNO, 1997). Toyoda Sakichi tinha como objetivo principal aumentar a eficiência através da eliminação de desperdícios. Ohno (1997) exaltou a relevância dos princípios contidos no STP por entendê-lo não somente como sistema de produção, mas também como sistema gerencial.

O pensamento enxuto é definido por Womack e Jones (2004) como uma forma de especificar valor, alinhá-lo na melhor sequência das ações que o criam, realizar as atividades sem interrupção toda vez que alguém as solicita e de forma cada vez mais eficaz. O termo Lean, que é traduzido como "enxuto" no idioma português, foi cunhado originalmente no livro "A Máquina que Mudou o Mundo" (The Machine that Changed the World), de Womack, Jones e Roos, publicado nos EUA em 1990. A Produção Enxuta ou Manufatura Enxuta refere-se a um paradigma de manufatura baseado na meta fundamental do STP, onde ser Lean implica esforço contínuo para o alcance de um estado caracterizado por desperdício mínimo e fluxo máximo (TAPPING; SHUKER, 2010).

Ohno (1997) identificou sete tipos de 
desperdícios que impactam um sistema produtivo no sentido de afastá-lo do ideal lean. São eles: i) Superprodução (produzir excessivamente ou cedo demais, resultando em fluxo pobre de peças e informações, ou excesso de inventário); ii) Espera (longos períodos de ociosidade de pessoas, peças e informações, resultando em um fluxo pobre, bem como em lead times longos; iii) Transporte excessivo (movimento excessivo de pessoas, informação ou peças, resultando em dispêndio desnecessário de capital, tempo e energia; iv) Processos inadequados (utilização do jogo errado de ferramentas, sistemas ou procedimentos, geralmente quando uma aproximação mais simples pode ser mais efetiva; v) Inventário desnecessário (armazenamento excessivo e falta de informação ou produtos, resultando em custos excessivos e baixa performance do serviço prestado ao cliente; vi) movimentação desnecessária (desorganização do ambiente de trabalho, resultando baixa performance dos aspectos ergonômicos e perda frequente de itens); e vii) produtos defeituosos (problemas frequentes nas cartas de processos, problemas de qualidade do produto ou baixa performance na entrega).

\subsection{Lean Office - $\mathrm{O}$ escritório enxuto}

O pensamento enxuto aplicado nas áreas administrativas passa a ser de vital importância, principalmente quando se constata que $60 \%$ a $80 \%$ de todos os custos envolvidos para satisfazer a demanda de um cliente são de natureza administrativa (TAPPING; SHUKER, 2010). McManus (2003) afirmou que é possível relacionar os princípios do pensamento enxuto às atividades não manufatureiras e tangíveis. O fluxo de valor, nesse caso, consistiria de um fluxo de informações e de conhecimentos, os quais possuem trajetória de valor mais dificilmente definida, se comparada a fluxos de materiais de uma fábrica. Ressaltou, todavia, que os desperdícios relacionados à informação são similares ao da produção enxuta: espera, estoque, superprocessamento, superprodução, transporte, movimentos desnecessários e defeitos.

Apesar de maior complexidade em se identificarem desperdícios em processos que não envolvam diretamente matérias-primas, máquinas e produtos, mesmo assim os resultados colhidos por empresas que já começaram a trabalhar com os conceitos do Lean Office são relatados como satisfatórios. Como exemplo, Herzog (2003) citou a empresa Americana Alcoa, maior produtora mundial de alumínio, que já possuía o sistema Toyota implementado e estruturado na produção há muitos anos, quando começou a implantar o conceito enxuto nas áreas administrativas. $\mathrm{O}$ segredo do sucesso na utilização dos conceitos foi considerar a informação como um produto. Esse autor relatou que a empresa tem apresentado grande evolução do sistema, aplicando os conceitos enxutos em fluxos inerentes às funções de RH, financeiro, compras e de contratos jurídicos.

Outro caso apresentado por Herzog (2003) foi a empresa Bosch, que a partir do mapeamento do fluxo de valor (MFV) percebeu as inúmeras circulações de informações entre as áreas envolvidas que não agregavam valor. Como solução para os problemas foram aplicadas várias técnicas para redução do tempo, com o intuito de se tornar o fluxo contínuo e sem paradas. A Bosch utilizou os conceitos em diversas unidades e promoveu melhorias em 32 processos administrativos. Segundo Turati (2007), o conceito do Lean Office pode ainda contribuir para fornecer melhorias no ambiente administrativo público, respeitando a estrutura organizacional. Citou, neste contexto, as muitas melhorias nos mapas de fluxo da Secretaria Municipal da Fazenda (SMF), do Município de São Carlos, Estado de São Paulo. Para Turati (2007), o grande avanço da aplicação foi para o cidadão, pois foi visível a redução do tempo de espera dos pedidos requisitados à prefeitura, com a eliminação das atividades que não agregavam valor; derivou-se maior agilidade na resposta aos clientes.

A implantação e manutenção dos princípios enxutos nas áreas administrativas são propostas por Tapping e Shuker (2010) em oito etapas: i) Comprometer-se com o Lean; ii) Escolher o fluxo de valor; iii) Aprender sobre Lean; iv) Mapear o estado atual; v) Identificar as métricas do Lean; vi) Mapear o estado futuro; vii) Criar planos Kaizen (melhoria contínua); e viii) Implantar planos Kaizen.

\subsection{Método e ferramentas do pensamento enxuto}

A sobrevivência das empresas no mercado depende da sua capacidade de atender às necessidades dos seus clientes (CAMPOS, 2008). O PDCA é um método de gestão que visa suportar o processo de solução de problemas e promoção das mudanças necessárias em tempo adequado. De acordo com o tipo do gerenciamento a ser realizado, 
o "giro" do PDCA assume características diferentes (Figura 1).

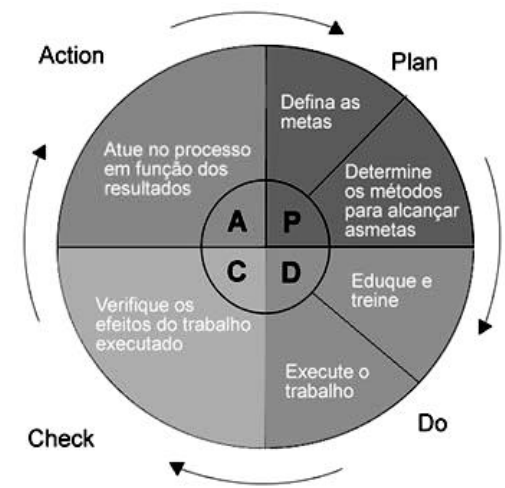

Figura 1 - Método PDCA: método de controle de processos Fonte: CAMPOS, 2008.

O método PDCA é constituído de quatro etapas (AGUIAR, 2002): i) Plan (Planejamento: definição da meta de interesse e planos de ação); ii) Do (Execução dos planos de ação: treinamento de pessoal, implantação e coleta de dados); iii) Check (Verificação: avaliação dos resultados obtidos em relação ao alcance da meta); e Action (Ação: sistematização das melhorias identificadas).

No contexto da produção enxuta, a aplicação do método PDCA visa atacar os sete tipos de desperdícios identificados por Ohno (1997). No suporte às etapas do processo de melhoria aplicado ao ambiente administrativo, algumas ferramentas demonstram-se especialmente importantes e devem ser destacadas:

a) Value Stream Mapping ou Mapeamento do Fluxo de Valor (MFV): Segundo Rother e Shook (2003 apud TURATI, 2007), o MFV é uma ferramenta que proporciona enxergar e entender o fluxo de material e informações através de um fluxo de valor. O fluxo de valor é toda ação que, agregando valor ou não, é necessária para passar um produto ou informação do estado de conceito para o estado de produto ou atividade finalizada. É uma ferramenta simples e exige apenas seguir o caminho da produção do início ao fim, desenhando-se, detalhadamente, o mapa de cada processo no fluxo de material e informação. Depois, através de um conjunto de sugestões, desenha-se o mapa do "estado futuro", uma representação visual de como o fluxo deve ser (ROTHER; SHOOK apud TURATI, 2007). Outras vantagens dessa ferramenta são: visão ampla de todo o fluxo, e não dos processos isoladamente; auxilia a identificação de desperdícios; mostra simultaneamente a relação entre os fluxos de material e informações; usa linguagem simples e comum para tratar os processos; torna as decisões visíveis, permitindo visualizar previamente possíveis alternativas de melhorias; e forma a base de um plano de ações. Os principais ícones do MFV utilizados neste trabalho estão especificados na Figura 2.

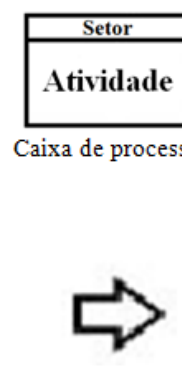

Fluxo do processo

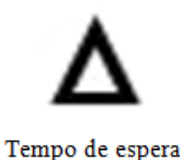

Tempo de espera

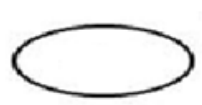

Início/Final do processo
Figura 2 - Ícones utilizados para o MFV aplicado no estudo Fonte: Adaptado de TAPPING; SHUKER, 2010.

b) Kaizen: representa a prática de melhoria, eliminando desperdícios e envolvendo os empregados. Permite às companhias baixar custos e melhorar a qualidade e variedade do produto (IMAI, 2010). Os benefícios para as empresas são: aumento de produtividade sem investimentos significativos; reduções nos custos de produção; capacidade de realização das mudanças de mercado; e motivação dos colaboradores. O kaizen requer mudança na percepção de todos na organização, que devem, constantemente, identificar desperdícios no trabalho para poder eliminá-los, sempre com apoio dos superiores (IMAI, 2010).

c) Cinco Sensos - 5S: O 5S, antes de ser uma ferramenta, é uma filosofia com o objetivo de preparação de um ambiente de trabalho para a qualidade. O $5 \mathrm{~S}$ representa as iniciais das palavras em japonês, que são: Seiri, Seiton, Seiso, Seiketsu e Shitsuke (UMEDA, 1997), que são assim descritos: i) Senso de Utilização (Seiri): Deixar apenas o mínimo necessário de material ou informações para o funcionário; ii) Senso de Ordenação (Seiton): Deixar o material a ser utilizado sempre disponível, sem precisar procurá-los; iii) Senso de Limpeza (Seiso): Conservar sempre limpo o ambiente de trabalho e os respectivos equipamentos; iv) Senso de Saúde (Seiketsu): relacionado à saúde física e mental, elemento fundamental para a felicidade de cada funcionário e também dos seus familiares; e v) Senso de Autodisciplina (Shitsuke): Consiste em adquirir e internalizar bons hábitos. 


\section{Metodologia}

A metodologia aplicada tem seus pilares na técnica de Pesquisa-Ação (PA). Para Coughlan e Coughlan (2002), a PA é uma abordagem de pesquisa que objetiva, concomitantemente, tomar uma ação organizacional e criar conhecimento ou teoria a respeito da ação tomada. Segundo Turrioni e Mello (2009), a sequência para condução da PA ocorre em cinco fases: planejar, coletar dados, analisar dados e planejar ações, implementar ações, avaliar resultados e gerar relatório. Há, ainda, o monitoramento como uma metafase abordada interativamente ao longo de toda a pesquisa. A PA demanda saber lidar com situações de exposição a uma realidade organizacional de constante mudança em tempo real. Este último ponto ressalta habilidades especiais para diagnose e intervenção (COUGHLAN; COUGLAN, 2002).

$\mathrm{O}$ monitoramento da fase de intervenção baseou-se no método PDCA, seguindo as etapas de planejamento, execução, verificação e ação. A Figura 2 detalha as atividades de visitação e intervenção organizacional. A identificação de uma organização que disponibilizasse informações administrativas e que, principalmente, oferecesse espaço para a experimentação organizacional proposta pela implantação do Lean office representou um grande desafio inicial. Pelo fato de tal implantação afetar significativamente aspectos relacionados à cultura e processos da organização de grande inércia, um ponto fundamental foi a redução do recorte de pesquisa de forma que se permitisse observar resultados iniciais no curto prazo que oferecessem dados conclusivos e relevantes para o estudo proposto. Dessa forma, a análise concentrou-se em um departamento específico, no contexto de uma empresa de pequeno porte.

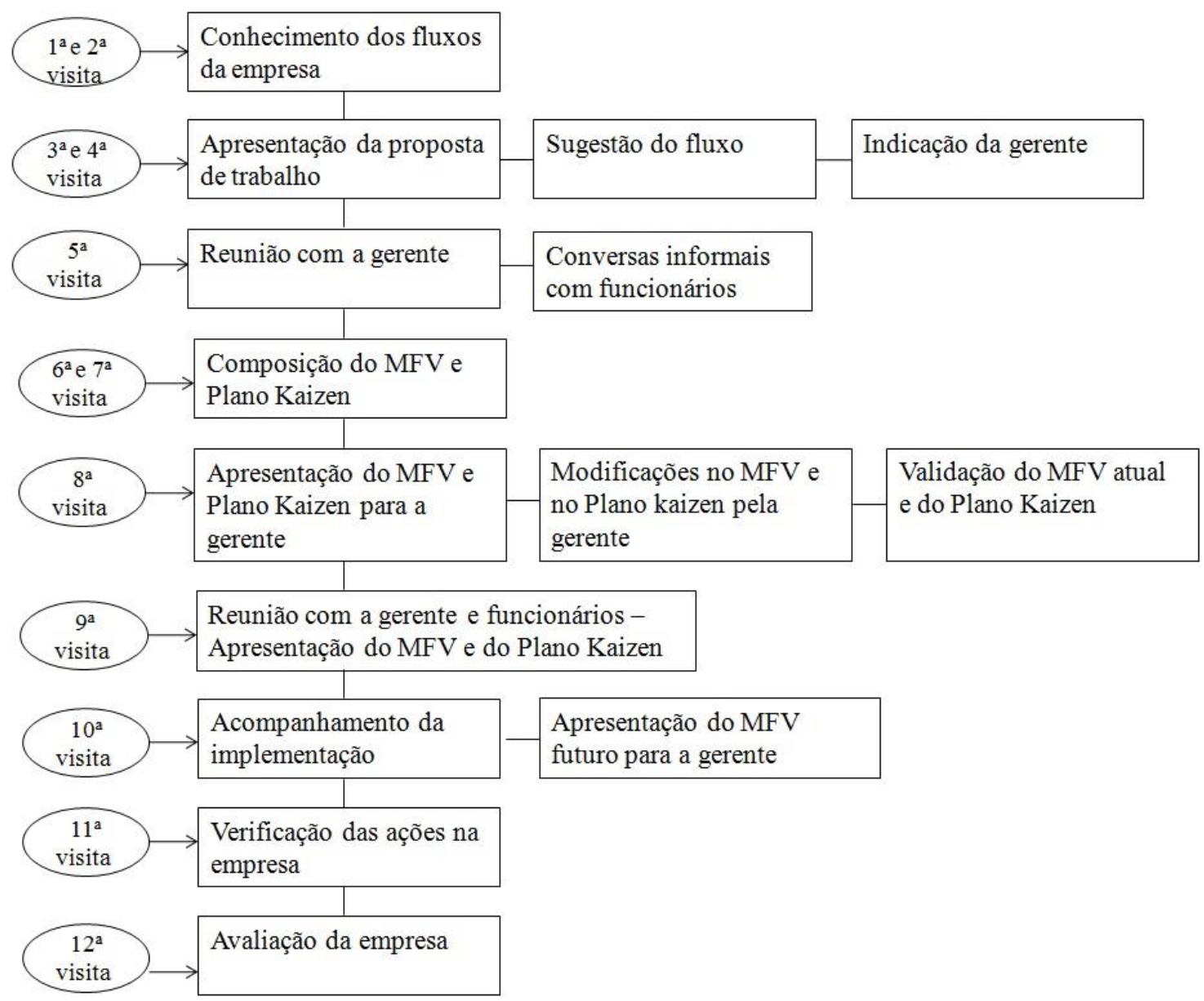

Figura 3 - Ação no ambiente de campo 


\section{Estudo de caso}

\subsection{Contexto da pesquisa de campo}

O caso estudado ocorreu em uma empresa de transportes. Foram analisados seus processos administrativos, com o fim de identificar um único processo que poderia ser utilizado em caráter de estudo-piloto para a compreensão da aplicabilidade da teoria estudada. Após um levantamento inicial que envolveu observação direta e entrevista com a gerência, puderam-se perceber mais claramente na área de expedição as oportunidades de identificação de perdas em espera, superprocessamento, movimentação, processos inadequados, inventário e transporte desnecessário. A área de expedição da empresa executava atividades referentes às viagens realizadas por sua frota e por terceiros. Segundo as informações levantadas, essa área teria experimentado recentemente um crescimento repentino dos serviços realizados por terceiros, o que ocasionou em diversos processos com evidências de desperdícios que estavam impactando todo o cotidiano da empresa. Um ponto de influência importante na análise foi o fato de a empresa já ter, à época do estudo, uma cultura $5 \mathrm{~S}$ relativamente bem disseminada.

Após a concordância com o estudo e intervenção por parte da gerência, houve comunicação formal acerca do trabalho na área definida, e a receptividade dos funcionários à iniciativa de intervenção foi também acolhedora e positiva. Contudo, houve dificuldades relacionadas a uma relativa resistência natural a mudanças propostas. Também, o fluxo intenso das atividades da área interferiu na disponibilidade dos funcionários na dedicação ao trabalho no decorrer do processo.

\subsection{Análise da situação inicial e plano de ação}

O MFV do estado atual da empresa partiu de diversas informações através da observação direta e de entrevistas informais com pessoas-chave do processo, como: diretor, gerente, supervisor e colaborador responsável pela atividade. Os passos seguintes foram na direção de identificar atividades do fluxo de valor do processo da expedição. Optouse por utilizar um modelo mais simples do que o apresentado por Tapping e Shuker (2010), no intuito de facilitar o entendimento e visualização do processo de estudo. $\mathrm{O}$ MFV anterior à intervenção pode ser visto na Figura 4.

As ações a serem implementadas são as métricas, que segundo Tapping e Shuker (2010) são determinadas visando à eliminação de desperdícios no fluxo, no qual depende da circunstância específica do fluxo de valor analisado. As métricas são sempre baseadas nos sete desperdícios. Uma métrica Lean eficaz é aquela que não só direciona um fluxo de valor para melhoria, mas a que pode ser estratificada em componentes, cada componente abordando um desperdício específico no sistema. Após as identificações das atividades com potenciais de melhorias, foi construído o plano de ação, que contempla as atividades passíveis de intervenção, o problema causado devido ao desperdício encontrado na atividade, o seu impacto no processo, as ação a serem aplicadas e o andamento de suas implementações.

As ações foram priorizadas de acordo com o seu grau de dificuldade de implantação, começando das simples às mais complexas, por supor que o ser humano tende a ser mais motivado quando visualiza o resultado das ações mais rapidamente. A análise da dificuldade de implementação das ações foi feita com o apoio do gerente do processo. O plano de Kaizen do processo de expedição estudado é apresentado na Tabela 1.

O mapa de valor do estado futuro é a previsão de como será o processo da expedição após a implantação de todas as ações propostas no plano Kaizen. Esse mapa é referência visual dos objetivos propostos de forma simplificada $\mathrm{e}$ esquematizada ao alcance de todos os envolvidos, proporcionando melhor entendimento. Através do plano de melhorias, foi possível montar o Mapa de Valor Futuro, acordado e alinhado com a gerência. $\mathrm{O}$ MFV mostrado na Figura 4 demonstra a eliminação de algumas atividades e a realocação de outras, derivadas das melhorias implantadas no processo. 

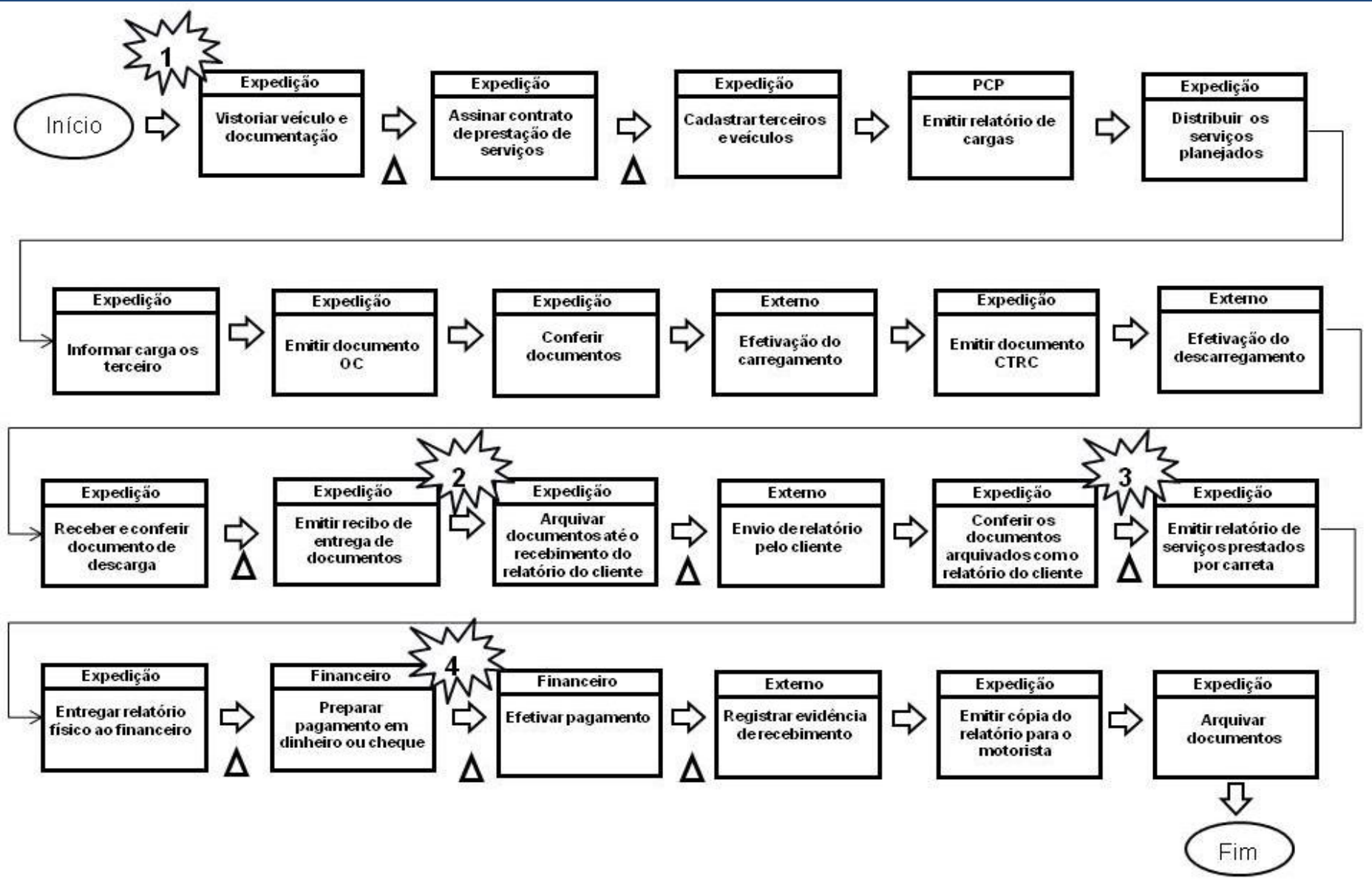

Figura 4 - Mapa de estado atual do fluxo de valor da expedição

\section{Resultados e discussão}

As oito etapas de implementação do Lean Office propostas por Tapping e Shuker (2010) foram aplicadas na implantação, com sucesso, da filosofia Lean em processos administrativos. Apesar de esses autores não mencionarem diretamente a relação dessas com o PDCA, a reflexão de tais etapas à luz do método científico proporcionou maior compreensão da análise crítica da maturidade do processo.

As etapas de 1 a 3 na proposta de Tapping e Shuker (2010) - comprometimento, escolha do fluxo e aprendizado do Lean - podem ser entendidas como decisões e atividades anteriores à implantação e guias para se adotarem os princípios do Lean num âmbito gerencial. Tomada a decisão, a etapa de planejamento $(\mathrm{P})$ do PDCA estaria mais relacionada com as etapas 4, 5, 6 e 7 (do mapeamento do estado atual até a criação do plano de ação), e a etapa de execução (D) seria relacionada diretamente com a etapa 8 (implantação das ações). A busca de coerência com o método científico sugere, então, a necessidade de considerar duas etapas adicionais no processo de implantação para garantir maior

coerência com o PDCA e melhorar suas chances de sucesso: a verificação dos resultados e a ação para garantir a sistematização das práticas de melhoria implantadas. Dessa forma, após o primeiro giro do PDCA se retorna à etapa 4 , de Tapping e Shuker (2010), promovendo a contínua identificação e implantação de melhorias que reduzam continuamente os desperdícios nesse processo. Tal perspectiva integrada da implantação do Lean Office com as etapas do PDCA é mostrada na Figura 5.

A identificação de desperdícios em processos administrativos evidenciou ter maior complexidade. De fato, Oliveira (2007) argumentou que a maioria das atividades nas áreas administrativas é relacionada à geração de informação, o que as torna atividades de natureza intangível. Com relação aos desperdícios observados, o de superprodução não foi identificado nos serviços da transportadora, fato esperado por se trabalhar somente por demanda na área analisada. Contudo, processos administrativos são passíveis de gerar excesso de papel, informações ou burocratização, que pode ser compreendido eventualmente como superprodução. 
Tabela 1 - Plano Kaizen da expedição

\begin{tabular}{|c|c|c|c|c|}
\hline \# & Problema & Impacto & Ação & Sem \\
\hline 1 & \multirow{6}{*}{$\begin{array}{l}\text { Todos os funcionários do setor } \\
\text { exercem todas as atividades da } \\
\text { expedição, independente de } \\
\text { elas serem ligadas a terceiros } \\
\text { ou da frota própria }\end{array}$} & \multirow{6}{*}{$\begin{array}{l}\text { As atividades não têm } \\
\text { padrão para serem } \\
\text { executadas. É visível a } \\
\text { falta de } \\
\text { gerenciamento,descentra } \\
\text { lização e conflito de } \\
\text { informações }\end{array}$} & $\begin{array}{c}\text { Segmentar as atividades da expedição por } \\
\text { tipo de serviço. Definindo funcionários } \\
\text { para trabalhar apenas com atividades } \\
\text { ligadas com terceiros ou com a frota } \\
\text { própria }\end{array}$ & 40 \\
\hline 1.1 & & & $\begin{array}{l}\text { Descrever o procedimento de execução das } \\
\text { atividades da expedição }\end{array}$ & 42 \\
\hline 1.2 & & & Definir os funcionários de cada segmento & 40 \\
\hline 1.3 & & & $\begin{array}{c}\text { Treinar os funcionários de acordo com o } \\
\text { procedimento }\end{array}$ & 42 \\
\hline 1.4 & & & $\begin{array}{l}\text { Sinalizar o local de atendimento de cada } \\
\text { segmento }\end{array}$ & 40 \\
\hline 1.5 & & & Divulgação das novas normas da expedição & 40 \\
\hline 2 & \multirow[t]{2}{*}{$\begin{array}{l}\text { Emissão do recibo de entrega } \\
\text { de documentação e } \\
\text { arquivamento desses } \\
\text { documentos }\end{array}$} & \multirow{2}{*}{$\begin{array}{l}\text { Demanda muito tempo } \\
\text { para a realização da } \\
\text { atividade. Custo com } \\
\text { aquisição de formulários } \\
\text { e pastas }\end{array}$} & $\begin{array}{c}\text { Definição de horário para a entrega dos } \\
\text { documentos após as } 13 \mathrm{~h} \text { do dia posterior } \\
\text { da realização da viagem, uma vez que o } \\
\text { cliente envia o relatório no dia seguinte ao } \\
\text { carregamento }\end{array}$ & 36 \\
\hline 2.1 & & & $\begin{array}{c}\text { Divulgação das novas normas de horários } \\
\text { da expedição }\end{array}$ & 42 \\
\hline 3 & $\begin{array}{l}\text { Fazer o relatório de viagens } \\
\text { realizadas por caminhão, de } \\
\text { acordo com os documentos de } \\
\text { descarga e relatório do cliente }\end{array}$ & $\begin{array}{l}\text { Demanda muito tempo } \\
\text { para a realização da } \\
\text { atividade. E aumento do } \\
\text { custo de impressão com } \\
\text { planilhas para } \\
\text { conferência }\end{array}$ & $\begin{array}{l}\text { Transformar o modelo utilizado para o } \\
\text { relatório do formato Word para Excel, } \\
\text { possibilitando, assim, a criação de link } \\
\text { entre o relatório e o arquivo do cliente }\end{array}$ & 39 \\
\hline 4 & \multirow{2}{*}{$\begin{array}{l}\text { Preparação do pagamento em } \\
\text { dinheiro ou cheque e sua } \\
\text { efetivação }\end{array}$} & \multirow{2}{*}{$\begin{array}{l}\text { Tempo do motorista } \\
\text { aguardando a } \\
\text { disponibilidade do } \\
\text { Departamento } \\
\text { Financeiro }\end{array}$} & $\begin{array}{l}\text { Definição de dois dias por semana para } \\
\text { realizar o pagamento, sendo este efetivado } \\
\text { através de depósito bancário }\end{array}$ & 38 \\
\hline 4.1 & & & $\begin{array}{l}\text { Inclusão de dados bancários no contrato de } \\
\text { prestação de serviço }\end{array}$ & 38 \\
\hline
\end{tabular}

O desperdício da Espera foi identificado em diversos momentos em que o serviço é solicitado com antecedência através de contratos firmados com terceiros. Também, é perceptível por documentos parados, pessoas em filas e esperas ao telefone. $\mathrm{O}$ desperdício de Transporte foi identificado, principalmente, no fluxo de comunicação (transporte da informação) quando superior ao demandado. O desperdício de Processos Inadequados foi percebido, por exemplo, em planilhas executadas em softwares de edição de textos. O desperdício de Inventário Desnecessário não foi identificado no caso analisado, mas é passível de ocorrer em outros processos da transportadora em que se encontra alto volume de arquivos antigos e outras informações em computadores e em forma física. A Movimentação Desnecessária foi visualizada em funcionários, levando e buscando documentos no Departamento
Financeiro devido a questões de leiaute e fluxos definidos na empresa. Já quanto a Processos/Produtos Defeituosos, esse desperdício pode ser identificado em registro de dados incorretos, erros em documentação e problemas de qualidade em serviços. 


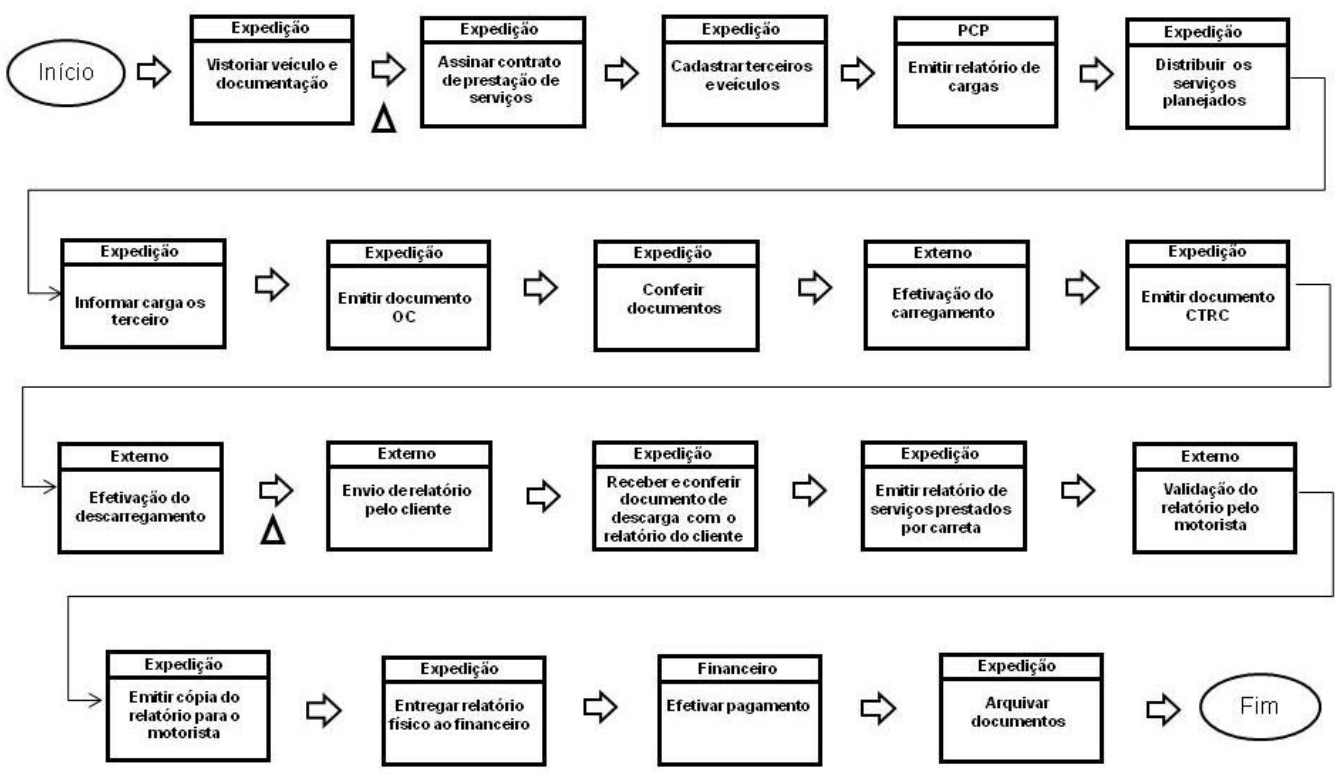

Figura 5 - Mapa de estado atual do fluxo de valor da expedição

$\mathrm{O}$ conceito enxuto aplicado às áreas administrativas ainda é pouco conhecido e explorado. Observou-se isso durante todas as etapas de desenvolvimento desse trabalho. Entretanto, foi possível perceber que o fato de a empresa já possuir a cultura do $5 \mathrm{~S}$ disseminada foi fator positivo na implantação da Lean Office. O trabalho com o senso de utilização, organização, limpeza, saúde e autodisciplina contribui relevantemente com a redução de potenciais de desperdícios. Outro fator positivo de possuir a filosofia $5 \mathrm{~S}$ na cultura da empresa é o fato de os funcionários estarem familiarizados e dispostos a trabalhar com conceitos que influenciam nas atividades cotidianas com o intuito de melhorá-las. Observa-se, contudo, que a empresa não apresenta alto nível de maturidade em todas as etapas do $5 \mathrm{~S}$, o que sugere a necessidade de difusão contínua da filosofia para o alcance de bons resultados.

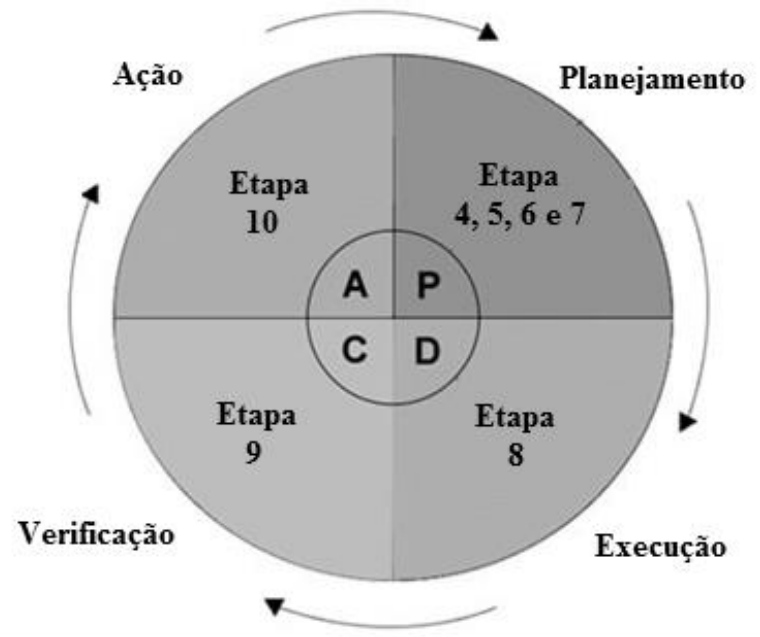

Figura 6 - Método PDCA e as etapas de implementação do Lean Office

\section{Conclusões}

Observa que a filosofia Lean já possui seu espaço na gestão das empresas e, com adaptações, pode ser aplicado a áreas administrativas, constituindo o Lean Office. Este desponta com possibilidades de motivar novos estudos acadêmicos, bem como gerar ambientes de trabalho com processos mais enxutos. Este trabalho procurou explorar a aplicabilidade do Lean Office através de um caso de intervenção real, resultando em melhorias perceptíveis nos processos administrativos de uma empresa de Transportes. Pode-se dizer que o Lean Office não é de fácil implantação. Todavia, o recorte reduzido da pesquisa de campo permitiu antecipar benefícios e 
visualizar barreiras importantes que ocorreriam em larga escala e longos períodos ao se tomar o contexto da empresa inteira ou, mesmo, uma empresa de porte maior para o processo de implantação.

A versatilidade da Engenharia de Produção permite que o profissional atue em diversas áreas de um sistema produtivo. Essa correlação fica cada vez mais visível quando filosofias como Lean, antes aplicadas apenas em áreas de manufatureiras, são adaptadas e têm sua aplicação viável também em funções administrativas de suporte. Conclui-se, ainda, que os conceitos do Lean Office apresentaram-se como promissores no recorte de campo analisado e são potencialmente extensíveis a diferentes setores e empresas, considerando as devidas adaptações contextuais relativas a cada organização.

\section{Referências}

AGUIAR, S. Integração das Ferramentas da Qualidade ao PDCA e ao programa Seis Sigma. Belo Horizonte: Editora de Desenvolvimento Gerencial, 2002.

CAMPOS, V. F. TQC: Controle da Qualidade Total no estilo japonês. 8. ed. Belo Horizonte: INDG, 2008.

COUGHLAN, P.; COUGHLAN, D. Action research for operations management. International Journal of Operations \& Production Management, v. 22, n. 2, 2002.

HERZOG, A. L. O escritório enxuto. 2003. Disponível em: <http://portalexame.com.br/revista/exame/edições/0789/gestã o/escritório-enxuto-43269.html>. Acesso em: 7 set. 2011.

IMAI, M. Kaizen Institute. 2010. Disponível em: $<$ http://br.kaizen.com/artigos-e-livros/artigos/kaizenbaixando-os-custos-e-melhorando-a-qualidade.html>. Acesso em: 5 maio 2011.

LEAN INSTITUTE BRASIL. 2011. Disponível em: <www.lean.org.br>. Acesso em: 25 abr. 2011.

McMANUS, H. Product development value stream analysis and mapping manual (PDVMS) - Alpha Draft. Cambridge: Massachusetts Institute of Technology, 2003.

OHNO, T. O Sistema Toyota de Produção: além da produção em larga escala. Porto Alegre: Bookman, 1997.

ROTHER, M.; SHOOK, J. Aprendendo a enxergar: mapeando o fluxo de valor para agregar valor e eliminar o desperdício. São Paulo: Lean Institute Brasil, 2003.

TAPPING, D.; SHUKER, T. Lean Office: Gerenciamento do fluxo de valor para áreas administrativas - 8 passos para planejar, mapear e sustentar melhorias Lean nas áreas administrativas. São Paulo: Leopardo Ed., 2010.

TURATI, R. C. Aplicação do Lean Office no Setor Administrativo Público. 2007. Dissertação (Mestrado em Engenharia de Produção) - Universidade de São Paulo, São Carlos, SP, 2007.

TURRIONI, J. B.; MELlO, C. H. P. Pesquisa-ação na Engenharia de Produção. In: MIGUEL, P. A. C. (Org.). Metodologia de Pesquisa em Engenharia de Produção e Gestão de Operações. São Paulo: Campus, 2009.

UMEDA, M. As sete chaves para o sucesso do 5S. Belo Horizonte: Fundação Christiano Ottoni, Escola de Engenharia da UFMG, 1997.

WOMACK, J. P.; JONES, D. T. A mentalidade enxuta nas empresas: Elimine o desperdício e crie riqueza. Rio de Janeiro: Elsevier, 2004.

WOMACK, J. P.; JONES, D. T.; ROOS, D. A máquina que mudou o mundo. Rio de Janeiro: Elsevier, 2004.

Artigo selecionado entre os 10 melhores do VIII Encontro Mineiro de Engenharia de Produção - EMEPRO 2012. 